\title{
Economic Responsibility Audit Transformation and Development of Township Party and Government Leading Cadres - Problems and Countermeasures
}

\author{
Li Tian* \\ Economic Responsibility Audit Service Center of Lanshan District, Linyi City, 276000, Shandong Province, China \\ *Corresponding author: Li Tian, 1sqsjj2021@126.com

\begin{abstract}
With the implementation of a series of policies to support rural development, such as the national rural revitalization strategy and poverty alleviation, the economic responsibility audit of township party and government leading cadres has been given new responsibilities and missions. However, some grass-roots audit institutions are faced with practical difficulties such as the solidification of audit thinking, slow progress of audit informatization construction, and large gap of grass-roots audit resources. The only way to overcome the difficulties is to explore the transformation of the economic responsibility audit and countermeasures of the township party and government leading cadres by tracing the source and adapting measures according to the difficulties.
\end{abstract}

Keywords: Township party and government leading cadres; Economic responsibility; Audit transformation and development

Publication date: October 2021; Online publication: October 29, 2021

\section{Introduction}

The township party and government leading cadres are the main body of rural governance; they are the promoters of rural revitalization strategy and poverty alleviation work as well as the main managers of major projects and funds in towns and townships. The supervision of fulfilling responsibilities is directly related to the people's livelihood as well as the economic and social development of the region. With a large number of leading cadres in China, who are facing opportunities yet with challenges of development and transformation, the realization of the innovative development of their economic responsibility audit, the improvement of the ruling ability of township party and government leading cadres, as well as the standardization of these party and leading cadres to effectively perform their duties have all become practical issues that need to be solved. With the rapid development of rural economy in the new era, the economic responsibility audit of township party and government leading cadres should also develop. From the perspective of strengthening the economic responsibility audit of the township party and government leading cadres in view of the actual situation of the region and the unit, this article discusses the relevant issues in the transformation and development, as well as seeks a solution to them ${ }^{[1]}$.

2. Requirements of the economic responsibility audit transformation of township party and government leading cadres in the new era

Based on the changes of major social contradictions in the new era, the layout of the national development strategy, the opinions on strengthening the construction of the audit supervision system, the relevant 
theoretical research results, as well as the investigation of some township party and government leading cadres, this article has summarized the requirements of the economic responsibility audit transformation of township party and government leading cadres in the new era from several aspects.

\subsection{Macroscopic view of the audit mode}

The office, party, government leading cadres, state-owned enterprises, and institutions main leading personnel economic responsibility audit regulations (hereinafter referred to as the regulations) require the economic responsibility audit work to earnestly implement the party and national decision deployment, closely promoting the five overall layout and four comprehensive strategic layouts, as well as implementing the new development concept. This means that economic responsibility audit should pay more attention to the macroscopic view and integrity of the audit concept and content.

\subsection{Digitalization of audit means}

The 13th Five-Year Plan requires audit institutions to speed up the construction of audit informatization and form a national audit cloud. The degrees of economic responsibility audit informatization and big data audit of township party and leading cadres directly determine the realization of the goal of full audit coverage and national audit cloud.

\subsection{Objectivity of the definition of responsibility}

Provisions have stressed that when defining the responsibility for the problems existing in the process of fulfilling their economic responsibilities, it is essential to stand by the perspective of development, use the principle of "three distinctions," and objectively define the responsibilities of the leading cadres. Township work directly serves the people at grassroots and it is in need of leading cadres with a sense of development and reform along with strong innovation. Therefore, the definition of responsibility needs to be more objective and accurate in order to mobilize the enthusiasm, initiative, and creativity of grass-roots leading cadres.

\subsection{Realize the full audit coverage}

The Opinions on the Implementation of Full Audit Coverage that was issued in 2015 clearly put forward the objectives and requirements of the full coverage of economic responsibility audit. Due to the limited staffing of audit institutions at grassroots level, the effective integration of audit resources is the only way to realize the full recovery and high-quality development of economic responsibility audit.

\subsection{Application of the new mechanism of audit results}

Township party and government leading cadres serve the front line. Their main duty is to do a good job in uploading and release as well as mass work. There is need to actively explore new mechanisms for the application of audit results, promote the supervision of the superior and the public, as well as give better play to the role of economic responsibility audit in the appointment, removal, and supervision of grassroots cadres.

\section{Problems existing in the economic responsibility audit work of the township party and government leading cadres}

There are regional differences in the economic responsibility audit business, which cannot be generalized. This study combined the economic responsibility audit project of $\mathrm{Z}$ Town Mayor carried out by L District 
Audit Bureau and found that the main economic responsibility audit work of township party and government leading cadres have the following problems ${ }^{[2]}$.

\subsection{Audit thinking mode}

From the implementation plan of the economic responsibility audit of $\mathrm{Z}$ Town Mayor, the content design is relatively comprehensive, the contents of macro-policy audit and micro-financial audit are relatively complete, but the problems in the audit report are concentrated on the traditional financial revenue and expenditure. The reason is that grassroots audit institutions are restricted by time, manpower, and thinking. In the actual audit process, the plan and the audit implementation are separated. The audit concept is still solidified in the micro and traditional financial revenue and expenditure audit. Major economic decisions such as macro-auditing and arrangements have not been substantially implemented. Therefore, the overall audit quality is poor and is unable to meet the needs of audit transformation and development.

\subsection{Slow digital transformation}

The digital transformation of audit requires investment in capital, time, personnel, etc. Talent is the key restriction factor. L District Audit Bureau has only 12 front-line auditors, and are older, most of whom have studied accounting. At the same time, the general business volumes of grassroots departments and units are small with very few state-owned enterprises, vertical management of the banking industry, not in the scope of the audit of county and district audit institutions, and there is no urgency of using big data audit. They are used to their familiar manual auditing methods, and for them to accept new concepts in transformation and development of economic responsibility audit, it would consume time. In addition, it would be challenging for them to use big data audit means to dig for clues in the audit.

\subsection{Large gaps in grassroots audit resources}

L District Audit Bureau has 295 non-audit work with only 12 front-line auditors. The 2020 Audit Project Plan includes 27 economic responsibility audit projects, 16 financial revenue and expenditure audit projects, 22 government investment projects, 5 budget implementation audit projects, and 5 tracking audit projects arranged at all levels. These do not include the temporary increase of superior audit institutions, special audit of supply and marketing system, or the temporary transfer of institution reform arranged by the district committee and district government. In addition, front-line auditors are often assigned to participate in crossaudits, special audits, and other projects organized by higher audit institutions, or in inspection work. Auditors are tired in terms of coping, difficulty in arranging their own learning and training, as well as lacking knowledge updates; thus, it is difficult to guarantee the audit quality.

\subsection{Uncertainty in the definition of responsibility}

Article III of the regulations defines the concept of economic liability. Article 40 and Article 41 stipulate the principle of audit institutions in determining the economic responsibilities of leading party and government cadres. However, the descriptions of the "due duties" and "major economic matters" of the leading party and government cadres are still relatively broad, requiring auditors to use their own professional judgment. This brings difficulties to the definition of grassroots auditors' responsibilities. In the past three years of all the economic responsibility audit projects of L District Audit Bureau, the majority of responsibilities have been defined as leadership responsibilities. In fact, the responsibilities of the secretary and the mayor of the party are almost the same. There is no clear standard of how many responsibilities the main party and government leaders should bear. 


\subsection{Lack of scientific and reasonable audit and evaluation system}

It is an important part of economic responsibility audit to conduct an objective, fair, and comprehensive evaluation of leading cadres. Throughout the audit evaluation by L District Audit Bureau on the economic responsibility audit of the township party and government leading cadres in recent years, it has been found that the evaluation of the economic responsibility audit of $\mathrm{Z}$ Town is basically similar. Moreover, most of them evaluate only on fiscal revenue and expenditure. There is generally a common problem of emphasizing revenue and expenditure over decision-making. Evaluations cannot be given according to the actual performance of their duties as it is difficult to ensure the comprehensiveness and accuracy of the performance evaluation of the economic responsibilities of the audited leading cadres.

\subsection{The application mechanism of audit results needs to be improved}

Provisions require the establishment and improvement of the result application system of economic responsibility audit notification, accountability, rectification, implementation, and results announcement. However, in terms of the application of audit results, L District has not yet established an economic responsibility audit results announcement system, and the economic responsibility audit results is only reported to the organization department and other relevant units, with a very limited impact. The audit results do not really affect the evaluation, appointment, removal, and adjustment of the audited subjects; thus, there is still a big gap between the requirements of transformation and development.

\section{Strengthen the path of the economic responsibility audit of township party and government leading cadres}

The above bottlenecks lead to the slow transformation progress of the economic responsibility audit of township party and government leading cadres. The audit quality is poor, and it is difficult to meet the requirements of rural revitalization and rural governance modernization. Therefore, there is a need for a long-term plan and overall design to explore effective solutions ${ }^{[3]}$.

\subsection{Strengthening the establishment of the audit team}

First, formulate a scientific and reasonable training plan. The training program should start with political construction in addition to ability and quality improvement along with the combination of political theory and professional skills learning. The contradiction between weak audit power and heavy audit task is difficult to solve in short-term, and it is impossible to investigate offline. At the same time, under the epidemic, face-to-face training is also limited, and grassroots audit institutions should make full use of online learning resources, organize self-learning, encourage learning while doing, and promote work by learning. Second, carry out research-oriented economic responsibility audits to create high-quality projects. Break the constraints between departments, between upper and lower levels, focus on key personnel, indepth study of audit ideas, macro audit content implementation, audit skills, etc., and then use key personnel and high-quality projects to drive the overall situation. Third, establishing an incentive mechanism. It is necessary to improve the management methods for year-end assessment, explore the inclusion of the above learning contents and results from the assessment in a quantitative form, as well as fully mobilize the enthusiasm of auditors.

\subsection{Strengthening the "two overall planning" work}

Further strengthen the plan management and do a good job in the "two overall planning" of audit projects and audit organization methods. Full cover does not mean average cover. In the case of insufficient audit 
strength, the audit subjects should be classified and managed according to the importance of mastering economic resources, economic and social development, as well as other factors. Key points should be clarified, and audit resources should be appropriately tilted to large-scale and large amount of capital units. On the other hand, in view of the flawed internal audit organization and varying skills of internal audit personnel, audit institutions should actively explore measures to strengthen their internal audit and social audit, designate personnel to guide internal audit, formulate relevant quality control mechanism, and make full use of internal audit results to purchase audit services from the society.

\subsection{Strengthening the definition of responsibility}

First, the facts should be clear. It should follow the requirements of the definition of "direct responsibility" and "leadership responsibility" in the regulations of the two offices along with the principle of consistent rights and responsibilities in addition to understanding the historical background, decision-making process, nature, consequences of the problems found in the audit, and the actual role of leading cadres. Second, the evidence should be sufficient. A complete chain of evidence should be formed according to the audit materials obtained. Reservations should be made on matters or audit evidence which have not been fully obtained. Third, the standards should be unified. Audit leaders should strictly check and encourage their auditors to carry out discussions. The regulations department and other relevant departments should consider in an overall manner in unifying qualitative standards and scales, so as to avoid different responsibilities of similar matters.

\subsection{Improving the audit and evaluation system}

The economic responsibility audit of township party and government leading cadres involves a wide range of areas, in which many departments are involved. Various evaluation systems cannot be simply applied. The situation of the township in the province has certain similarities. It is possible to combine the characteristics of the township in the new era and the experience of economic responsibility audit of the township party and government leading cadres in recent years. In regard to the economic responsibility audit of township party and government leading cadres, it is important to explore the establishment of an evaluation system, make effort to achieve the organic combination of common and personality, macro and micro, qualitative and quantitative, as well as regularly revise and improve the evaluation in line with the situation of different towns and townships to achieve the purpose of a comprehensive, objective, and fair evaluation of the performance of township party and government leading cadres.

\subsection{Innovating the mechanism for the application of audit results}

The application of audit results can be strengthened by organizations, discipline inspections, supervision commissions, and other joint meetings, while taking the audit results as an important reference for the assessment, appointment, removal, reward, and punishment of the audited leading cadres. The establishment of audit rectification as a specific indicator of high-quality development assessment should be explored. In addition, points should be deducted for towns which do not implement responsibilities with inorganized rectification or failed to report audit rectification results. For units with outstanding issues, failed to rectify on time, practiced fraud, or refused to rectify, the discipline inspection commission or organization department should interview the responsible comrades and provide feedbacks if necessary. The units or leaders who have caused significant impact or losses due to ineffective rectification should be held accountable. 


\section{Disclosure statement}

The author declares that there is no conflict of interest.

\section{References}

[1] Roya E, 2019, Difficulties and Countermeasures to College Internal Economic Responsibility Audit. China CPA, 176(01): 163-165.

[2] Huang Q, 2019, Case Study of Economic Responsibility Audit of Party and Government Leading Cadres in Z County. Southwest University of Political Science and Law.

[3] Lu Q, 2020, Difficulties and Countermeasures in Internal Economic Responsibility Audit of Radio and Television Media Units - Takes Internal Economic Responsibility Audit of J Radio as an Example. Audit and Finance, 400(11): 36-37. 